\title{
Coercive Metaphors in News Headlines: A Cognitive-Pragmatic Approach
}

\begin{abstract}
This article explores the application of metaphors in news headlines with a view to interrogating their potential for coercion. Coercion in news discourse is understood as a strategic deployment of pragma-linguistic devices, including metaphors, to foreground the representations of socio-political reality that are compatible with the interests of the news outlet rather than those that inform public debate. It is argued that coercion can be exposed through systematic discourse analysis. Methodologically, the study aims to integrate the cognitive and pragmatic approaches to metaphor in regarding it as both a conceptual building block of news representations and a strategic framing device in news discourse. A quantitative and qualitative analysis of a sample of metaphors excerpted from a corpus of 400 most-read headlines from one of the most visited English-language newspaper sites The Daily Mail is conducted to illustrate such coercive applications of metaphor as simplification, imaging, animalization, confrontation, (de)legitimization, emotionalization, and dramatization. In the course of the analysis it is demonstrated how certain ideologically-biased representations can be coerced through figurative language.
\end{abstract}

Key words

Metaphor; headline; coercion; critical discourse studies; Daily Mail

\section{Introduction}

Even with its spatial restrictions and institutional conventions the headline has to realize several functions at once: introduce the issue covered in the news article, generate audience's interest in it, and indicate the news outlet's attitude towards it. The latter function is linked to the outlets' attempts at framing issues in specific 
(sometimes self-interested) ways with the aid of selected linguistic, stylistic and rhetorical resources. ${ }^{1}$ Apart from being studied for their clipped forms and conventional puns, headlines have also been researched in terms of, for example, their potential to construct newsworthiness (Bednarek and Caple 2012), and for their sensationalizing capacity (Molek-Kozakowska 2013). This paper is part of a larger project ${ }^{2}$ that explores the properties of headline style from the perspective of potential coercion, focusing on the implications of specific discursive strategies that compress information and frame interpretations. Here I look mainly at how metaphors can be used to influence the representations of socio-political reality in news discourse. The rationale is that the economy of expression inherent in metaphoricity comes at the cost of foregrounding (profiling) some representations at the cost of others. As a result, this project can be located closer to the critical end in the spectrum of diverse approaches within discourse studies.

Out of many linguistic devices used to compress meaning in the headline, I look in detail at metaphor, which, whether conceived of in terms of conceptual mapping, blending, or mental simulation of embodied experience, is regarded as an inherent and pervasive property of human cognition. Thus, metaphoricity of verbal expressions has been productively studied by cognitive linguists. But in this paper I also want to make a case for integrating the cognitive and pragmatic orientations in discourse analysis (for a similar approach see Hart 2010). Metaphor is not only a cognitive but also pragmatic phenomenon, since its perlocutionary effects and felicitous uses are as important to study as its embodied bases or cognitive structuring. Moreover, the stability of conventionalized metaphors is often central to pragmatically efficient interaction. The discursive reproduction of figurative representations facilitates the building and management of collectively shared mental models, which van Dijk terms "social cognition" (1998). Last but not least, with respect to news discourse particularly, there is a need not only for a description of how metaphors tend to be applied, but also for the critical interrogation of some their ideology-laden applications. This is because, potentially, they can be used as strategic devices to reproduce social inequality in public communication (van Dijk 2001, 2006). In my perspective, the coercive, rather than just communicative, function of metaphor in media discourse needs to be exposed, specifically if some metaphors are demonstrated to have been pervasively used to forward representations that are in tune with the (profit-oriented) interests of news outlets, to the detriment of the public debate.

On a methodological note, I argue here for an integrated cognitive-pragmatic approach to investigating coercion in news discourse in order to, among other things, help increase the systematicity and exhaustiveness of critical methodologies of media studies. With the media constructing, rather than just reflecting, our social reality, more attention needs to be devoted to how exactly language is recruited to this aim. Arguably, critical approaches to discourse analysis have never been so socially relevant and yet, no matter how insightful they are, they are sometimes dismissed for their alleged lack of objectivity and replicability. In this paper, I illustrate my arguments for a cognitive-pragmatic agenda in media 
discourse studies with a qualitative analysis of applications of metaphor in news headlines. The sample that has been subject to such critical analysis was drawn from a special-purpose corpus of 400 "most-read" news items in the online version of the popular British mid-market tabloid Daily Mail compiled in 2012.

\section{A critical approach to coercion in discourse}

Discourse analysts recognize language use to be of primarily transactional, rather than just representative or expressive, nature. Thus, they look at how linguistic choices are guided by pragmatic ends, and what cognitive effects these choices are designed to achieve. To investigate this, they not only describe language elements that have been selected to be used in a discursive encounter, but also interpret their functions in that context and explain their social implications and constraints (Fairclough 1995). This is particularly important in the cases when language tends to be used to naturalize political dominance or even legitimize power abuses (van Dijk 2001).

To use terminology derived from functional linguistics, any discursive encounter is treated as a conjunction of language options that have ideational, interpersonal and textual meta-functions (Halliday 1985). Hence, a set of linguistic elements that enforces a biased representation of reality, an unequal relationship between the sender and the receiver, and a deceptively acceptable textual logic is likely to work coercively. For some critical discourse analysts, coercion ${ }^{3}$ is one of the linguistic realizations of the meta-strategy of persuasion, particularly frequent in the case of political and mass-mediated discourse (Chilton 2004; CharterisBlack 2005; van Dijk 2006; Hart 2010). It originates with the institutional communicator's intent to influence the knowledge, beliefs and attitudes of the collective of recipients by constructing semiotic representations in such a way that they serve the former's own interests. It often relies on the sender's exploitation of the position of power or trust, together with their privileged access to various symbolic resources that can be drawn on to magnify the effect on the receivers. Obviously, the resources offered by language are of our interest here.

Critical discourse analysts have shown that there is a range of pragma-linguistic resources that can be employed strategically by institutional communicators to forward a given representation of reality. According to a classification by Hart (2010), these resources can be generally grouped as referential strategies (e.g., labelling, categorization), predicational strategies (e.g., attribution, qualification, verbal and nominal transformation, implicature/presupposition) and proximization strategies ${ }^{4}$ (e.g., indexicals, verbal and nominal indicators of positioning and movement, adverbial indicators of space and time). The strategically crafted representation can then be reinforced by the application of specific legitimizing techniques (e.g., internal/external coherence). The pervasive application of such strategies in social communication is explained by Hart (2010) with reference to evolutionary psychology and cognitive science. In such a way it is possible to 
describe how an ideologically invested representation of reality can be imposed, for example by means of specifically tailored metaphors, deictics or patterns of epistemic modality. Methodologically, Hart's (2010) approach significantly "tightens" the procedural framework of critical discourse studies.

As coercion is claimed to be the aim of many institutional discourse encounters, it is also likely to be found in the context of news mediation. ${ }^{5}$ For example, Hart (2010) illustrates the interaction of various coercive strategies within a large corpus of news articles, showing how a biased representation and negative evaluation of immigrants is forwarded in the British mainstream conservative press. In my study, coercion is analyzed solely with respect to the strategic potential of headline metaphors to shape the receivers' perception of the covered issue. When located in the headline, some metaphors can be recruited by media producers to (mis)represent reality to suit their interests (e.g., to increase circulation, manifest political support, engage readers' attention and affect, strengthen reader loyalty). If such uses of metaphor bear marks of consistency and pervasiveness, I treat them as possibly contributing to re-shaping of receivers' cognitive models of socio-political reality. Consequently, it is imperative to start interrogating their coercive potential systematically and critically. It needs to be pointed out, however, that coercion here is not taken to mean manipulation in its most insidious sense of making the receiver do something that is against their best interests (van Dijk 2006). Since I do not study the effects of reception of headlines (actual perlocutionary effects), I regard coercive metaphors as ones that have a high potential of making recipients accept representations that are congenial to the interests of the media industry more than of any other institution or social group.

Since the aim of this project is elucidating the discourse functions of metaphors in headlines, followed by their critical assessment in terms of the strategic potential for coercion, the study can be situated at the intersection of cognitive and pragmatic orientations to media discourse. In addition, my objective is to contribute to developing ever more systematic methods of verifiable textual criticism. Importantly, criticism is not to be thought of as either outright condemnation or subjective judgment, but rather as an attempt at interrogating the categories and mechanisms that usually escape notice without deeper analytic insight or interpretative reflection. Institutionally, denying a critical stance in media studies amounts to a kind of hypocrisy, as hardly any account of mediation (which is a type of symbolic reinterpretation itself) can be claimed to be ideologically neutral. Moreover, as critical theorists have often argued, any academic description of a status quo helps to ideologically legitimize that status quo by virtue of implying its validity as an object of institutionalized inquiry (cf. Bernstein 1991: 16). Arguably, a critical approach in media studies research is of high social relevance in the increasingly complex, disparate and media-saturated world. 


\section{Metaphor: A cognitive building block and a strategic framing device}

In classical rhetoric metaphor is one of the master tropes, i.e., figures of speech that may directly impinge on thought. It is described as a stylistic device that consists in presenting one entity by associating it with the qualities of a different entity, mainly to impress recipients. In this study metaphorical expressions are not treated as decorative rhetorical devices that enhance the experience of reception, but as potentially powerful triggers of specific conceptualizations, some of which may be ideologically charged. This section reviews the main strands in current research first on cognitive and then on pragmatic aspects of metaphor and revisits selected studies that prove that metaphor can indeed be a coercive mechanism in newscasting.

The idea that metaphors are not just decorative embellishments but key building blocks of human thinking has been taken up by cognitive linguists, notably Lakoff and Johnson (1980), who illustrate the pervasiveness of metaphorical conceptualizations in all kinds of (con)texts. From the cognitivist perspective, metaphor is seen as a result of conceptual mapping from a source domain (usually a more tangible and universalized domain of experience) to a target domain (usually a more abstract or specialized domain). It is noted that language expressions used to talk about the target domain are reflections of profiled characteristics of the source domain entity, such as is the case in the exemplary LIFE IS A JOURNEY metaphor formula, with "don't look back" or "being at the crossroads" idioms. The nature of the correspondence between the two conceptual domains in metaphorical relations preoccupies many cognitive scholars and is still subject to debate (e.g., Are they drawn online or based on long-term memory, built on the basis of prototypes or membership categories, obtained depending on salience or systematicity of characteristics?). Until fairly recently, cognitive linguists/semanticists focused primarily on describing and explaining metaphorical representations made available by a given language and culture (Krzeszowski 1997). Many have chosen to study metaphorical thinking at the conceptual, as well as neural, level (Lakoff 2008), rather than at the discourse level, which would call for a more context-dependent and pragmatically informed orientation (Stern 2008). In this study, cognitive-linguistic categories are treated as conceptual benchmarks for analytic procedures adopted to expose discursive coercion.

Theoretical considerations on metaphoricity so far have concerned the pervasiveness of metaphorical thinking as a construal operation (cf. Gibbs 2008). For example, conceptual metaphor theory has been instrumental in explaining some of the cognitive (as well as affective) preferences users have for specific conventional metaphors established in the lexicon and phraseology of the English language. Some are traced back to the principles of embodied cognition, according to which our sensory perceptions, our ways of orientation in space, or our experiences of movement and balance, for example, are responsible for the structuring of our "primary" metaphors, such as MORE IS UP, SIMILAR IS CLOSE or KNOWING IS SEEING (Grady 1999). These, in turn, build our most abstract 
concepts, such as CAUSATION for example (Johnson 2008). Additionally, a more recent theory of metaphorical representation, blending theory (Coulson 2001; Fauconnier and Turner 2002), sees metaphor use as a more complex mechanism of merging, rather than mapping, of characteristics of at least two discursive "input spaces," which share enough similarities (belong to the common "generic space"), to be conducive to constructing a coherent and relevant "blended space." The theory reduces the implication of previous approaches that metaphors are largely source-driven. Blends arise as selective projections from input spaces as a result of composition, completion or elaboration, for example. In the course of blending, new meanings can be construed "online" out of apparently random elements and still make sense through inference, implicature or contextualization. Consequently, blending theory seems to offer the perspective to move the theory of metaphor from the domain of semantics to the domain of pragmatics of discourse comprehension/production (cf. Coulson 2001; Hart 2010). In this study I take metaphorical mapping to be a specific, relatively simple case of metaphorical blending. Assuming that coercion through metaphor is likely to be instigated by fairly straightforward, even simplistic, representation, I expect to find more two-domain mappings than over-complex blends, particularly while investigating such a type of text as the news headline.

As all other pragma-linguistic devices, metaphors are instantiated in specific discursive contexts to realize a specific pragmatic purpose. Hence, when analyzing them here, we need to bear in mind the linguistic, generic, institutional and socio-cultural allowances and constraints on metaphor use in headlines. According to Stern (2008: 262), the boundaries of the pragmatics of metaphor are set by semantics (i.e., the recourse to the literal meaning) on the one hand, and context (i.e., the constraints on ambiguity) on the other. Although activating the literal meanings of the lexical items realizing a metaphor is indispensable, the reader infers that the expression is likely to mean something beyond itself (much like in the case of demonstratives or indexicals), according to Stern (2008: 270). The context and background knowledge must be then relied upon in the process of interpretation. The pragmatic aspects of discourse, for example, speech acts, conversational maxims, recognition of mutual intentions or relevance mechanisms underlying "loose" language (approximation, substitution, category extension or narrowing), are drawn on by recipients to arrive at the emergent meaning appropriate to the given context. Since human communication is inferential, rather than based on decoding (Sperber and Wilson 2008: 87), the pragmatic relevance principle is likely to be in operation in metaphor comprehension, as is the case with interpretation of other types of expressions. This means that the cognitive effect of interpreting a metaphor is going to be dependent on the judgments of its relevance vis-à-vis various contextual factors (e.g., textual meta-function, communicative purpose, institutional embedding) and the processing effort involved in the interpretation. Finally, as linguistic expressions involving metaphors may be comprehended or missed, judged as correct or wrong, as well as evaluated for appropriateness, humor or beauty, metaphor seems to be very much a feature of 
language use that is relative to the preferences (interests) of the users. Thus when studying the coercive potential of metaphor, the analyst is positioned to assess the aptness of metaphor (e.g., against the background of other textually entrenched and contextually pre-eminent representations) in order to explain the implications of specific instantiations of conceptualizations.

In a study devoted to coercive metaphorical patterns applied in headlines, attention should be paid to the role of conventionalized metaphors, which constitute a prime example of meaning-compression devices. They are likely to function as triggers to elaborate background knowledge representations (e.g., scripts, schemata, models) and are often chosen by editors because of their "resonance" with the public. Cognitive linguists as well as relevance theorists concede that conventional metaphors, unlike original or poetic ones, tend to be processed relatively quickly and effortlessly (Coulson 2001; Lakoff 2008; Sperber and Wilson 2008), which may explain their coercive potential, already marked in some studies (cf. Goatly 2007: 40; Jeffries 2010: 21; Hart 2010: 145-167). That is why the present study explores metaphors together with their embedded presuppositions, since in a sense both are important ingredients of final representations of news items, many of which are built on the basis of verbal input that activates mostly "given," not "new," knowledge. It is hypothesized here that relying on conventionalized conceptualizations (as well as on easily retrievable "common" knowledge) is typical of communicators that intend to reproduce representations by facilitating a relatively unreflective processing of verbal input. This, in turn, is one of the main mechanisms of coercion.

To problematize this kind of unreflective acceptance of mass-mediated metaphorical representations, some discourse analysts argue for a more critical scrutiny of metaphors in public communication (e.g., Charteris-Black 2005; Goatly 2007; Hart 2010: Jeffries 2010). They advocate a type of study which, besides identifying, classifying or comparing metaphors, would also demonstrate how they help to reproduce, naturalize and legitimize specific ideologically biased representations. Some metaphors, both conventional and novel, have already been proved to work coercively when applied strategically in political discourse. For instance, in one of the first comprehensive studies of metaphor in political discourse, Chilton (1996) demonstrates how metaphors were applied for the conceptualization of policy proposals to seek wider resonance, such as the CONTAINMENT metaphor propounded during the Cold War (or during the "war on terror" to use a more recent example, cf. Molek-Kozakowska 2009). Alternatively, in his corpus-based study, CharterisBlack (2005) demonstrates which metaphors were selected by charismatic political leaders (from Winston Churchill, to Martin Luther King, Jr. to George W. Bush) to effectively mobilize large portions of citizenry to support their policies. That is why the cognitive-pragmatic view on metaphor I advocate here is conducive to criticism, as it includes not only an account of metaphors' linguistic realizations, salience and distribution, but also their likely cognitive and social imports.

These cognitive and social effects appear to be the starker the more such metaphors are mediatized and institutionalized. To use terms drawn from relevance 
theory, such metaphors yield cognitive effects with minimized processing efforts. That is why henceforth I look at studies devoted to interrogating coercion via metaphor in news discourse. Literature reviewed below demonstrates the use of metaphor as a strategic framing device used to reproduce specific ideologies. First, metaphors have been exposed as a means of perpetuating racist beliefs. For example, Santa Ana (1999) reveals evidence of negative other-presentation in a metaphor IMMIGRANTS ARE ANIMALS underlying the reporting of immigration issues in the U.S. and intensifying in the context of populist electioneering. Likewise, Sandikcioglu (2000) finds metaphors and metonyms that show contrasts between positive self-presentations of WESTERNERS epitomizing civilization, power, maturity, stability and RATIONALITY, and negative other-presentation of the ORIENTALS associated with barbarism, weakness, immaturity, instability and thus IRRATIONALITY. Secondly, with respect to European politics at the turn of the twentyfirst century, a range of issues related to the legitimizing function of metaphors in the press has been addressed by Musolff (2004). He notes a relative pervasiveness of "body politic" metaphors, according to which the STATE IS A BODY with SOCIAL GROUPS AS BODY PARTS and various SOCIAL PROBLEMS AS DISEASES to be cured through specific POLICIES AS REMEDIES. Such "medicalized" representations of official policies may effectively displace oppositional proposals. Subsequently, many CDA studies have focused on the rhetoric of immigration discourse (e.g., Reisigl and Wodak 2001; Richardson 2007; Hart 2010). Specifically, Charteris-Black (2006) evidences the surge in instances of conceptualizations of BRITAIN AS A CONTAINER in right-wing discourse, and the use of such metaphor for the legitimizing of antiimmigration policies. This is compatible with earlier findings by Lakoff (2002) that right-wing political solutions seem to be represented and justified morally by virtue of fitting in with a popular STRICT PARENT schema, while liberal ones tend to be accepted by those who favour the NURTURANT PARENT imagery.

An important area of consideration with regard to coercive discursive strategies is the role of myths, symbols and metaphors in sustaining cultural hegemony. Some media-oriented work has been done on cross-cultural dimensions of metaphorical mappings. For example, Fabiszak (2007) in her diachronic corpusbased analysis of print war coverage in Poland and Britain shows how the similar metaphorical representations of war tend to be pervasively used by the press to debase and vilify the enemy (ENEMY IS AN ANIMAL), euphemize war brutality (WAR IS THEATRE/GAME), and legitimize warfare (WAR IS CLEANING), despite cultural and ideological differences. In fact, Kövecses (2005) discusses both variability and universality of some metaphorical representations arguing that what needs to be further scrutinized in metaphor research is not only the universally shared embodied experience that is the major source of metaphorical mappings, but also the language- and culture-specific contexts and discontinuities that induce unique conceptualizations. It is important, thus, to nuance analyses rather than to emphasize findings that confirm the cross-cultural similarities of metaphorical cognition: metaphors may have similar cognitive bases, but fairly varied discursive realizations. Acknowledging that is quite important in the era of media 
globalization and conglomeration, with likely dominance of Anglo-American cultural representations. For example, it has been demonstrated that the "aggressive" capitalist business model is ideologically and morally legitimized in business media through a cluster of "evolutionary struggle" (e.g., FIGHTING, FEEDING, MATING) representations with respect to business mergers and acquisitions (Koller 2005). Likewise, Herrera Soler's (2008) analysis of metaphors in English/Spanish corpus of business magazine headlines shows a common metaphorical basis for DOING BUSINESS in terms of A CYCLE OF LIFE, with input from the plant and animal world, natural phenomena and human activity to represent the mechanisms of trading, competition, economic growth, recession or profit making. This kind of conceptualization may result in the ultimate legitimization of some business practices, which are projected as natural and inevitable rather than as ideologically invested.

Although the above review by no means does justice to the extensive and growing body of research on metaphor in both theoretical and empirical strands of discourse studies, I hope to have shown some of the dimensions of the interplay between the cognitive aspects of metaphorical representation and the pragmatic, even coercive, applications thereof in media discourse. To reiterate, this overview was designed to revisit the conceptual framework of metaphor research, together with the shifting disciplinary preoccupations therein, and the mutual correspondences between cognitive and pragmatic analytic apparatuses. All this was to show how and why metaphor ought to be approached critically as a potentially coercive category in news discourse.

\section{Illustrating the use of coercive metaphors in headlines}

\subsection{Sample and procedure}

Headline style has long been a subject of scrutiny within both media studies and discourse studies for its peculiarities in linguistic structure, its potential for framing, keying or priming of interpretations, its role in collecting attention and its implications for coercion (Bell 1991; Richardson 2007; Herrera Soler 2008; Bednarek and Caple 2012; Molek-Kozakowska 2013). This study uses a selection of headlines to identify some of the ways in which metaphors tend to be used coercively. It must be stated that the following examples are to be treated as exemplification rather than evidence of coercion. The examples were selected in the course of a manual quantitative search and a qualitative analysis of a special purpose corpus of headlines garnered from the online version of the British mid-market tabloid Daily Mail ${ }^{6}$ throughout 2012 (120 headlines were collected in January, 120 headlines in May, and 160 headlines in December). Thus, the sample that was subjected to metaphor identification consisted of 400 headlines compiled from the most-read list ${ }^{7}$ of news items featured on the Mail Online. The corpus amounts to about 21,530 words, as, besides headlines, sub-heads and 
lead-ins (if any) were also included, for example to elucidate the contrived wording of the headlines. ${ }^{8}$ These headlines were coded for non-literal expressions by three coders (a researcher in linguistics, a graduate student and myself), by means of such criteria as register incongruity, word class incongruity, or collocation incongruity, and subsequently extrapolated to their conceptual mappings.

However, instead of taking the maximalist approach to identification of metaphorical usages on the basis of the meaning of individual lexical units (cf. Pragglejaz Group 2007), we focused on contextual and co-textual meanings of multiword units. We took metaphors mostly to be represented by relations between collocates whose literal meanings did not apply in the given context. Further on, we excluded overt similes/comparisons, classical idioms (unless their phraseology was significantly modified and thus a new meaning was created), phrasal verbs and lexical units whose basic meaning has been rivaled by a conventionalized metaphor (e.g., "to see something" meaning "to know something"). Using this "minimalist" approach, we identified 97 headlines $(28+30+39)$ with instances of figuration (image schemata, metaphors, blends, metonyms), which was approximately one-fourth of the whole corpus. Note that we did not attempt to count all instantiations of metaphorical meanings, since, as can be seen in the examples below, a metaphor could transpire throughout the headline via various phraseological combinations. Within the sample we subsequently marked (i) creative/novel metaphorical units and (ii) conventional metaphors - fixed collocations that border on idiomaticity (e.g., "to struggle with poverty") and which are found in dictionaries (e.g., Macmillan English Dictionary for Advanced Learners) and through corpus searches. The ratio of creative to conventional metaphors was roughly 1:3. This (nevertheless) relatively high number of creative metaphors can be attributed to the semantic opacity of many headlines which are designed to attract attention to the article.

As regards the procedure for the extrapolation from the phrasal to the conceptual level of metaphor identification, the three coders compared their intuitions and negotiated the conceptualization of domains (e.g., BLOW) and formulas (e.g., REFORM IS A BLOW). Needless to say, this phase of metaphor identification is a question of intersubjective interpretation rather than finding an empirically objective pattern, and by no means is to be treated as "the only possible" formulation (cf. Charteris-Black 2005: 27-29). When in disagreement, the coders confronted their intuitions with linguistic and extra-linguistic data (e.g., headline's contextual meaning, properties of news discourse, main themes of the article) and subjected their choice to a vote.

As regards identifying the pragmatic applications of metaphors for a subsequent critical analysis, the discourse function of identified figures (coercive or not) was determined in the course of a focus group discussion between 12 graduate linguistics students and myself. Most conventional metaphors were judged to have been used for purely representational or explicatory purposes. However, some of the headlines included metaphors which were assessed to have a potential to conjure up ideologically charged representations. The following sec- 
tion is a qualitative analysis of fifteen selected headlines featuring the metaphors the focus group recognized as potentially coercive (by agreeing that they unduly distorted the issue covered). It offers a critical interpretation of exemplars of coercive strategies realized by metaphorical expressions. The fifteen highly-ranked exemplars represent various coercive strategies, which could be labelled here as simplification (reducing a complex entity to a simple one), imaging (using primary image schemata for abstract entities), animalization (mapping animal attributes onto humans), confrontation (presenting interpersonal relations/stakeholders' interests as inherently oppositional and conflict-laden), (de)legitimization (adding to or reducing the value of something by means of representing it as a more/less positive entity), emotionalization (drawing from affect-laden source domains), and dramatization (mapping routine processes/entities onto extreme/ superlative ones).

\subsection{Results: Metaphor-based coercive strategies}

\section{Simplification}

It should not come as a surprise that some of the most common metaphorical patterns of headline style derive from the preferences for mapping the embodied physical experience onto the abstract political and social reality. This is a useful device to project an unknown and complex situation in terms of, for example, a fairly straightforward spatial schema arrangement. The following headline draws on the shared experience of unobstructed movement, as opposed to blockage, and of the use of various degrees of force to open containers/passage (all italics added).

(1) We would use force to keep Gulf open: Hammond warns Iran not to block key oil route: Defence Secretary warned Tehran regime that $U K$ will not tolerate the 'very significant consequences' of a threat to block the Strait of Hormuz. ${ }^{9}$

Not surprisingly, OPENNESS is often metaphorized as accessibility and evaluated positively (viz. open-access resources), while BLOCKAGE, in many contexts, is associated with obstruction of movement that normally should be continued. The presupposition introduced with the factive verb warn activates a script in which Iran had already blocked or is now blocking the navigation in the Gulf. Moreover, in the headline, quite conventionally, metonymy (Teheran for Iranian government officials) and personification (the $U K$ as a political decision-maker/ military agent) are resorted to, to present the diplomatic tensions as an interpersonal conflict - a verbal ARGUMENT verging on physical confrontation complete with warnings and threats. It can be observed that this kind of metaphoricity is typical of newspaper headlines that simplify and dramatize issues; however, another potential coercive effect of such metaphor choice consists in reproducing 
and sustaining the ideology of inherent political conflict and cultural polarization between "us" and "them," as represented by WESTERNERS and EASTERNERS. This, incidentally, is primed with the ambiguous initial personal pronoun we. More on confrontational framing through metaphors is below.

Another insidious way of simplifying the issue is to project a complex political controversy in terms of a choice of whether to be "with us" or "against us". In the following headline, a breach in the conservative party discipline is conceptualized as REVOLT or REBELLION (all italics added):

(2) The great gay marriage revolt: 118 Tory MPs set to defy Cameron and trigger biggest Tory party rebellion in modern times. ${ }^{10}$

With this kind of projection, one can wonder whether democratic deliberation, diversity of stances and subsequent consensus-seeking are still to be practised, or if the ruling political force is predicated on uniform obedience to an authoritarian leader. Calling any form of opposition to the party leader as rebellion/revolt implies a highly regrettable situation in which all attempts at rational argumentation have failed and no concessions can be envisioned any longer. In addition the words have strong unpleasant associations with violent military conflict and physical destruction, which construct newsworthiness through negativity (Bednarek and Caple 2012). Unquestionably, such headlines sell papers, but they tend to cancel the idea of multi-party deliberation and consensus-seeking as the essence of democracy in the public mind and reduce politics to a for-or-against power game.

\section{Imaging}

The use of universally shared image schemata and embodied metaphors is not restricted to the coverage of abstract political processes and decisions. In fact, it comes very handy in scientific accounts of new discoveries and inventions as well. For example, the dramatic import of the recent findings about the receding mental competence that comes with aging is intensified with metaphorical expressions pertaining to MOVEMENT DOWNWARD, as in (all italics added):

(3) How the brain starts going downhill at 45: Scientists find mental decline sets in much earlier than they had thought: British men and women suffer the same 3.6 per cent loss between the ages of 45-49. Whilst older men aged 65-70 fare worse with a 9.6 per cent drop in comparison with the 7.4 for their female counterparts. ${ }^{11}$

The negatively evaluated image schema of MOVEMENT DOWNWARD is instantiated in (3) through such verb and noun phrases as "going downhill," "a decline sets in," "fare" or "a drop." Its recurrent application, coupled with the strategy of using numbers and percentage figures for credibility, intensifies the dramatic effect of 
visualization of gradual brain Loss. In addition, the two presupposition triggers the initially placed pronoun "how," and the comparative expression "much earlier" - make it a scientific fact that, after they turn 45 , the majority of people are not nearly as mentally fit as they used to be. This may be true in some cases, but here the process of mental incapacitation is projected not only as universal but also as SNOWBALLING, particularly with the visualization of ever quicker "downhill" roll. Arguably, an insidious social consequence of such a coercive presentation of the results of a relatively mundane piece of scientific research is that it can give substance to the ideology behind the discriminatory practices of ageism.

Imaging an abstract entity or a process is rarely innocent or detached from the ideological stance of the imager. The powerful effect of imaging the invisible via a marked way of metaphorization can be noticed in the following headline (all italics added):

(4) Britain will be 'swamped' by TB unless high-risk immigrants are routinely given blood tests, experts warn. ${ }^{12}$

Despite the use of inverted commas (scare quotes) that are supposed to show the publishers' distance to the used phrase, the psychological effect of imaging an influx of infected immigrants in terms of a destructive and uncontrollable NATURAL DISASTER has been achieved. This is congruent with extant schemata of immigration projected through CONTAINER and LIQUID metaphor formulas (Charteris-Black 2006; Hart 2010). The negative conceptualization of immigration is reinforced: lexically by the fairly unspecific modifier "high-risk," syntactically by the conditional structure that leaves Britain with no alternatives, and rhetorically by the recourse to (unspecified) expert sources. Such images are likely to perpetuate stereotypes of immigrants as backward (infected with a disease that has allegedly been eliminated in the First World), irresponsible (not likely to be even aware of their condition unless forced by law to take a blood test), and dangerous (inflicting an epidemic on the British). It can be hypothesized that the coercive effect of imaging immigrants in a stereotyped manner, which is congruent with media outlets' profit-seeking through sensationalist coverage, has been achieved here relatively effortlessly.

\section{Animalization}

The presentation of human qualities and behaviours by comparing them to animals is a figurative device found in various domains of discourse, from poetry to medicine (for politics, cf. Chovanec 2010). Animalization metaphors have also been found in the Daily Mail's corpus of headlines, for example when an institution/organization is represented as a "watchdog," and is thus likely to incorruptibly scrutinize public policies, or when a politician is qualified as a "hawk" and thus likely to enact tougher policies than other officials. However, a case that is far more coercive is a tendency to represent (alleged) CRIMINALS AS ANIMALS (i.e., not fully human) (all italics added): 
(5) Federal agents hunt for 'Jane Doe' child sex abuser: Nationwide appeal to trace woman seen in horrific internet film - and to rescue her young victim. ${ }^{13}$

(6) Notorious sex offender on the run: Police issue alert as woman raped in own home by attacker who kicked the door in. ${ }^{14}$

Headlines that represent (suspected) offenders as HUNTED ANIMALS are rooted in the collective memory of rural communities protecting farmyards and farm animals from predatory wolves, foxes or other pests. Alleged criminals represented in this way acquire qualities of instinctive aggressiveness, inclination towards uncontrollable violence, as well as lack of any scruples or moral principles. To complete the HUNT imagery, the "victims" of such "predators" are identified and public warnings issued. By implication, the police/law enforcement agencies are projected as entitled to do anything to apprehend such individuals, because scaring or chasing them away will not do. The metaphor has a coercive potential of instilling the belief that some people do not deserve to be treated humanely and no regrets would be felt if such criminals were killed "on the run" (which transpires in some readers' responses and comments underneath the article).

Animalization metaphors (of evil people) may be contrasted with personifications of (innocent) animals, routinely applied in environmental and animal-rights discourse, which resonates with many Mail Online's readers. This is exemplified by a multilayered personification (of a female orang-utan) and animalization (of hunters) in the following headline (all italics added):

(7) Don't hurt my baby! Pregnant orang-utan protectively hugs her daughter as ruthless Borneo bounty hunters move in for the kill. ${ }^{15}$

In a way, this type of figuration caters to the feelings of cultural superiority of WESTERNERS with their awareness of animal issues and sensitivity to imperatives of environmental protection. By the same token, some countries of the developing world, whose "primitive" economies (based on hunting) and ineffective governments let exploit the natural world and deplete biodiversity, are negatively evaluated as exceedingly "savage" and greedy. Animalization metaphors have the coercive potential of dehumanizing the Other, and providing justification for some racist/supremacist attitudes.

\section{Confrontation}

Some discourse analysts claim that the Western culture is predicated on confrontation both in its material and symbolic dimension (Tannen 1999). Indeed, looking at many of the Daily Mail's headlines, one could have an impression that Britain is in the constant state of waging war. This is because the wAR metaphor formula is used (abused) in the coverage of a range of issues, for example in presenting 
and legitimizing policies that fight unemployment, hospital bureaucracy, teenage crime, or currency fluctuations. Not surprisingly, studies reveal that WAR is a commonly used source domain for conceptualizing anything from internal political dissent to international diplomatic tensions, from economic competition to ethnic or cultural inconsistencies, from terrorism to drug-peddling (cf. Charteris-Black 2006; Fabiszak 2007; Goatly 2007; Hart 2010). From the following headline, we learn that there is also a "war" between Britain and the EU (all italics added):

(8) Europe's war on British justice: UK loses three out of four human rights cases, damning report reveals. Ten Tory MPs call on Prime Minister to take action. Say there is a need to 'end rule by judges'. In 350 cases, Britain has lost 271 and been successful in only 86 . Timing of report coincides with three controversial upcoming rulings. David Cameron promises to take personal charge of the issue. ${ }^{16}$

Since the covered issue relates to the legal system, we can observe how two intertwined metaphorical representations of conflict are used to enhance the presentation. These are LOSING A COURT CASE IS LOSING A BATTLE and SUBJECTING BRITISH JUDICIARY TO EUROPEAN COURT'S REVIEW IS LOSING SOVERIGNITY, which together constitute a reinforcing cluster of a sort (cf. Koller 2005). These metaphors, in turn, feed into the conceptualization of the PM as someone solely responsible for "taking charge" to prevent the British defeat in the war waged by European institutions against the British justice system.

Such kinds of WAR representations may coerce the readers into believing in inherent and long-standing antagonistic relation between Britain and the rest of Europe. This can be counted as a prime example of coercive media-sponsored misrepresentation, as historically speaking, there has not been so far a more successful political project to ensure peace and foster cooperation among disparate peoples than the European Union (despite many criticisms it receives). Apparently, this rationalization falls into oblivion if we consider the premium put on confrontation in the Western tradition. Additionally, confrontational representations perpetuate the current trend of "personalization" of politics, in which individual leaders are assigned praise or blame for larger processes and unpredictable developments that are usually beyond their control (cf. Fowler 1991). Needless to say, such a simplistically personalized portrayal of politics is championed by popular media, purportedly to make citizens more involved in political issues. However, personalization of politics, unless confronted critically, may be ultimately detrimental to a democratic public sphere. ${ }^{17}$

\section{(De)legitimization}

Media discourse is a prominent domain where cultural hegemony and political dominance are legitimized. Legitimization is understood here both broadly as 
fostering commitment to cultural and political structures that favour the growth of commercial media, and in a narrow sense of lending support to a specific political platform. Delegitimization is the opposite strategy of invalidating claims and disqualifying actions by a group that represents antagonistic interests/ideologies (cf. van Dijk 1998; Chilton 2004; Cap 2006; van Leeuwen 2007, Chovanec 2010).

It can be observed that one of the most prominent themes in British tabloid coverage is the condition of the welfare state. For example, the Daily Mail relishes in exposing the paradoxes of the system of taxation and redistribution of wealth through benefits, as well as the lowering quality of the services the state is supposed to provide. The recent economic crisis has brought the issues of costefficiency, competency and productivity to the foreground, as the following headlines illustrate (all italics added):

(9) Cameron: I'll soften the blow of child benefit cuts for higher earners...: PM's vow to tackle unfairness in system. Plans will see it stopped for families where one parent earns over $£ 42,375$. But Mr. Cameron says he wants to get rid of the 'cliff edge'. ${ }^{18}$

(10) Bad teachers should be sacked 'in weeks': Gove wants parents in classrooms to help drive up standards: Education Secretary wants to scrap rules which shield incompetent staff. ${ }^{19}$

(11) Nurses must be told to 'talk to patients': PM's intervention is a damning indictment of care on our hospital wards: Nurses should check whether patients need help at least once an hour. David Cameron says quality of care has been hit by the stifling bureaucracy. ${ }^{20}$

All the three headlines feature numerous presuppositions about the British welfare state: that the child benefit reform is outrageously unfair, that schools are full of incompetent teachers who cannot be fired, and that the care in NHS hospitals is really poor as nurses do not check on patients frequently enough. To add drama to this bleak vision, several (clustering) metaphors are recruited, notably REFORM IS A BLOW (if it was introduced by Labour government), JOB SECURITY PROVISIONS ARE A SHIELD for incompetent employees, HOSPITAL PROCEDURES ARE OBSTACLES TO CARE. It might be observed that this cluster of metaphors consistently represents progressive politics as harmful and makes Labour responsible for the deterioration of the state.

In addition, all the headlines inform us that David Cameron, or one of his top ministers, has personally intervened to remedy the situation. What is left out of focus is that the "intervention" consisted in merely expressing a desire, an intention or a wish for the situation to change in the future. Nevertheless, a distorting juxtaposition of two social realities is forwarded: the current sorry state and the prospective government-initiated change. A potentially coercive psychological 
effect of engendering undeserved support for the government (just because they see a problem and wish it would disappear) may be achieved here. Incidentally, the vivid, even though relatively conventionalized, metaphors, enforce the effect by projecting the conservative GOVERNMENT AS PROTECTORS in the physical sense (in partial overlap to what Lakoff (2002) finds about conservatives). Thus, David Cameron is there to "soften the blow" people are to be struck with anyway when it comes to cutting benefits, or, on another occasion he promptly intervenes when hospital wards are "hit" by the "stifling" bureaucracy, whereas his Education Secretary Michael Gove is dispatched to eliminate "shields" that the bad teachers guard themselves with.

\section{Emotionalization}

Popular news media outlets achieve the impression of relevance and importance of their coverage by resorting to emotionalization. ${ }^{21}$ Admittedly, much of the news coverage on any given day does and should engage readers emotionally, but in some circumstances certain emotional reactions are artificially generated by newscasters, either to align the readers with their own interests, or to displace rational arguments in the public debate. This is understood here as coercive emotionalization and, as shown below, it is sometimes realized via metaphorical patterning. In our sample, the strategy seems to be implemented most often with the aid of representations drawn from such affect-laden domains of experience as finance and health. Linguistically, emotionalization may also be realized through emotivity in lexical choice (Bednarek and Caple 2012), the use of attributions, stylistic and register shifts, syntactic parallelism and textual highlighting. Most of them are evident in the following example (all italics added):

(12) IMF 'to boost bailout fund to \$1TRILLION' as World Bank slashes growth forecast and warns of return to 2008/09 downturn: British taxpayers could face footing part of bill: (...) World Bank slashes global growth forecast from $3.6 \%$ to $2.5 \%$. Warns 'Europe is probably already in recession'. 'If euro debt crisis escalates, global growth will be 4\% points lower'. Cashstrapped Greece to rent out ancient ruins to pay for their upkeep. ${ }^{22}$

The announcement of the planned increase in IMF's reserve funds covered here is followed by a sequence of disparate estimates, warnings and speculations. Hyperboles are not uncommon, with what is metaphorically dubbed as a "slash" in "growth forecasts" actually amounting to a reduction by $4 \%$ at most, but probably by just $1.1 \%$. The macro-economic predictions, some expressed in consonance-marked jargon (e.g., "warns of return to (...) downturn"), are juxtaposed with home-budget vocabulary (e.g., "footing the bill," "cash-strapped," "pay for upkeep"). One of the "unfair" presuppositions, reinforced by further logical inferences, is that ultimately the British taxpayer will be forced to pay for the 
excessive European debts in the encroaching recession. This misrepresentation may be coerced through the confusing terminology: reduced growth is still growth, not recession. Yet, the readers of such convoluted headlines are likely to assimilate the information presented in the emotionalized home-budget vocabulary, not the economists' jargon and confusing numbers. What is interesting from the perspective of this study is that this headline uses a conventionalized metaphor in its central presupposition, namely it takes it for granted that economic GROWTH (a metaphorical transfer from the domain of nature) is an indispensable feature of the thriving capitalist system. Paradoxically, the conventionalized metaphor is so deeply entrenched and so generally accepted that we no longer ask what would happen if a living organism continued to grow indefinitely. This might also explain why an alternative discourse - that of sustainable development, rather than unstoppable growth - is backgrounded by the press.

Emotionalization is achieved not only through commonly used explicit references to emotion ("fear," "horror," "surprise"), but also by an aggregation of affect-instigating metaphorical patterns. See (all italics added):

(13) Manufacturing slowdown and lower exports heighten fear of a triple-dip recession. ${ }^{23}$

Relying on extant studies (e.g., Lakoff and Johnson 1980; Krzeszowski 1997; Grady 1999), it is assumed here that orientational schemata and MOVEMENT metaphors are tied to certain positive or negative evaluations. Here, the readers' anxiety about the state of the British economy may have been raised by a consistent reliance of imagery that is oriented DOWN and DOWNWARDS (e.g., "slowdown," "lower," "dip"). This is compounded by pejorative associations of such concepts as unwelcome slowness, sudden and unexpected downward movement entailed in a "dip," or the imaging of diminishing amount or backward movement inherent in receding. On the whole, it can be observed that business and economic news featured on the Daily Mail's website tend to be marked by artificially contrived affectivity and exaggeration.

\section{Dramatization}

It is not uncommon for popular press to dramatize coverage to increase circulation. Our sample demonstrates that the Daily Mail is likely to use metaphorical lexical patterns (mainly exaggerations resulting from incongruous collocations) for that purpose as well, for example to sensationalize Christmas party season as "carnage," a work dismissal as "claiming the scalp," a court case as a "battle," or road repairs as "chaos." Another example is (all italics added):

(14) Cosmetic face filler timebomb: Doctors call for crackdown over rising toll of women scarred by botched skin treatments. ${ }^{24}$ 
The dramatic announcement in the headline above represents a certain kind of aesthetic procedure - injecting a face filler - as nothing short of life-threatening. The words "toll" and "bomb" enable the readers to construct a mental image of an explosive device that, when placed under skin tissue by an incompetent practitioner, is likely to go off and kill or maim the patient at some point in time. (This might also be considered as an example of the strategy of coercive imaging discussed above.) None of this is true, but the effect of constructing an attention-grabbing coverage has been achieved. Interestingly, the survey of "plastic surgeons' opinions" had been conducted by the Daily Mail itself, even though its results are generalized as representative of the current state of knowledge. Paradoxically, instead of losing credibility by dramatizing the issue out of proportions, the outlet can actually be credited with voicing a warning about the dangers of the filler treatment, despite naming only one patient who complained about the procedure. Due to the use of metaphors as primary vehicles for drama, the outlet avoids accusations of publicizing incorrect information. As a result, such headlines may coerce the readers into treating the outlet as a trustworthy institution whose interests are aligned with the interests of the general public and stay loyal to it, believing that its alarmist speculations are legitimate warnings.

Since the domains of PHYSICAL WELL-BEING and FINANCIAL STABILITY are so productive, let us close the analysis by examining a headline whose (fairly conventional) metaphoricity may have interesting political and cultural implications. In example (15), and in accordance with the confrontational pattern identified above, a distinction is made between the healthy financial situation in the UK, as opposed to the critical condition of some of the Eurozone members. The medical parallels in the economic coverage are relatively conventionalized, and presumably do not call for too high processing efforts, as every reader is likely to be familiar with perceptions of well-being on the one hand, and indisposition, pain and various symptoms of common diseases on the other. The following headline, reporting on the annual economic summit in Davos, features a similar metaphor of currency value ratings and investment risk estimates being conceptualized in terms of HEALTH HAZARDS (all italics added):

'At least we've our own currency': Prince Andrew pokes fun at EU nations suffering from collapse of euro: Duke of York said foreign firms should invest in Britain as 'unlike other Euro nations it is open for business'. ${ }^{25}$

It can be deduced from the salient metaphorical conceptualization here that some nations have irresponsibly consented to having their currency replaced with euro in a botched OPERATION, which led to their new currency's "collapse" and caused the nations' subsequent "suffering." The coercive implication of this metaphorical pattern is that it may be potentially extended to imply ideologically invested claims. One of them is that these nations are now convalescing and thus closed to business and investment. Actually, economic stimulation through investment is what those nations need very badly now and, in the end, Britain (as represented 
by its elites) is exposed as wanting to exploit their misfortune to maximize its own gains.

\section{Conclusions}

This study was designed to show some of the coercive functions that metaphor can be put to in newspaper headlines. To generalize, let us repeat that most metaphors in headlines are relatively conventionalized mappings, blends, or even clusters used for representational and explicatory purposes. These figures need to be fairly stable and easily retrievable for popular press consumers who appreciate positive cognitive effects at relatively low processing efforts, to use relevance theoretic terms. However, on closer inspection, some figurative devices may have far-reaching consequences for framing the readers' interpretations of covered issues, and, in the long run, transforming their mental models of elements of sociopolitical reality. This is what I assume to be the coercive potential of metaphor in this study.

The majority of coercive metaphors discussed here was sourced from embodied experience (e.g., the CONTAINER or MOVEMENT image schemata) and recruited universally shared "primary" metaphors, which ascribe stable evaluations to common mappings (e.g., DOWNWARD MOVEMENT IS BAD). The recurrence and salience of metaphors pertaining to relatively well-known domains of experience, such as ARGUMENT, WAR, HUNT, PROTECTION, GROWTH, HEALTH, FINANCE is notable. The choice of metaphors in headlines was demonstrated to be functionally related to the purpose of simplifying issues, (including stereotyping of ethnic groups), imaging complex and unique abstract processes in terms of general schemata, dehumanizing individuals by attributing animal properties to them, polarizing social/national groups, legitimizing or delegitimizing political solutions, emotionalizing economic issues, or dramatizing relatively trivial coverage.

The coercive function of metaphors, as shown here, can consist in producing ideology-laden cognitive effects, some of which amount to stereotyping, perpetuating discriminatory or nationalistic attitudes, distorting political and economic issues, or engendering the negative feelings of anxiety, resentment, fear or blame. However, it needs to be stressed that metaphor is coercive inasmuch as recipients accept the instantiated conceptualization as apt or felicitous for example when they activate a matching frame, say of REFORM as something that hurts rather than helps, of police investigation as a HUNT, or of GROWTH that is desirable at all times rather than only to a certain extent. Arguably, highly conventionalized metaphors hinder reflective critical questioning of such representation, so they need to be spotlighted first of all to raise awareness of coercion. In addition, coercive metaphors are those that entail presuppositions and involve evaluations that are hard to challenge, for example that some criminals are not fully human, that the members of a political party should agree with the leader, that the British welfare state has disintegrated, or that confrontation is the typical relation between nations/ 
cultures. Importantly, it was also shown that metaphors and other devices (labels, collocations, presuppositions, nominalizations, modifiers and qualifiers, syntactic structures) in given headlines may reinforce each other to produce coherence that is central to the effect of naturalization of coercive representations. The wealth of observations obtained from such a relatively small textual sample (15 coercive exemplars out of 97 identified figure-laden headlines out of 400 most-read headlines) may lead to the conclusion that more attention ought to be paid to verifying other possibly coercive functions of metaphor, for example its role in generalizing, trivializing, concealing/obscuring, personalizing, aesthetizing, defamiliarizing or mythologizing issues.

Methodologically, this study was aimed to show the applicability of an integrated pragma-cognitive framework of critical discourse analysis as a productive approach to studying media discourse. With this in mind, the theoretical part of the paper was expanded to review the current state of research on metaphor, which has been extensively theorized and sufficiently operationalized as an analytic category in the cognitive and pragmatic literature. To complete the argument, I revisited selected landmark (critical) studies of media discourse that had exposed some of the insidious applications of metaphor in various textual arrangements. It emerges that, when studied in the context of newscasting, metaphors need to be approached critically, not only descriptively, due to a likelihood of them being used coercively. This requires a systematic qualitative analysis rooted in the pragma-cognitive framework of discourse analysis.

The notion of coercion, as adapted from Hart (2010), was used to integrate cognitive and pragmatic conceptual apparatuses. More generally, coercion relates to the linguistic realizations of the overall strategy to influence recipients' mental models of socio-political reality through specific representations instantiated and promulgated in public discourse. Media communicators, it is claimed, are in a privileged position to forward representations that suit their own interests (cf. van Dijk 2006). These may be tied to various ideological positions including institutional, economic, political priorities, as well as class, race, ethnic, national or other affiliations. Indeed, the task of exposing these latent biases in media discourse, as realized through various coercive linguistic mechanisms, is being continuously undertaken by critical discourse analysts. Arguably, critical approaches to mediated communication have never been so socially relevant, despite the fact that they are sometimes eschewed as not thoroughly replicable, or dismissed as politically biased themselves. The present study makes a case for a validation of qualitative critical analysis that is rooted in accepted strands of linguistic research (e.g., cognitive linguistics and pragmatics), relative to welltheorized models (e.g., conceptual metaphor theory, discourse theory, relevance theory), based on well-delimited categories and tied to a synthesizing functional concept (i.e., coercion). 


\section{Notes}

1 For an overview of research on the linguistic properties of "headlinese," see, e.g., Bell (1991), Reah (1998), Bednarek and Caple (2012: 100-104), or Chovanec (2014: 117-121).

Besides metaphors, the use of other pragma-linguistic devices that have coercive potential, particularly presupposition and nominalization, has been explored.

3 The notion of coercion has been selected, instead of, e.g., manipulation, hegemony or ideology, primarily due to its better delimitation and analytic applicability. I am not oblivious to alternative theoretical constructs and analytic categories in other ideology-oriented strands of critical research (cf. Molek-Kozakowska 2011, 2012), a review of which is beyond the scope of this project.

For more details on the role of proximization in the context of legitimization see Cap (2006). By no means is it claimed that all recipients are equally likely to fall prey to media communicators' coercion efforts, but various theories and research studies of media influence (e.g., priming, agenda-setting, cultivation) indicate general patterns of media shaping recipients' cognitive models.

According to Audit Bureau of Circulations UK, comScore, and Journalism.co.uk, the Mail Online had overtaken the New York Times as the world's most visited English-language newspaper site in January 2012, with traffic at the level of approximately 100 million. Studies show increases in its circulation with 119 million readers globally in April 2012, 42 million of whom were in the UK, nearly 900,000 readers of its iPhone app and more than 500,000 using the Android app. (http://www.journalism.co.uk/news/-wnc13-mail-online-publisherreaches-36-of-uk-population-every-week/s2/a553171/)

Three/four days a week, ten top headlines were collected from the list of "most-read" articles, which is, in my opinion, representative of the material that actually reached the recipients. In the subsequent examples, headlines, sub-heads and lead-ins (if any) are separated with colons

9 Retrieved from http://www.dailymail.co.uk/news/article-2082887/We-use-force-Gulf-openHammond-warns-Iran-block-key-oil-route.html

A note on notation in the analytical part: ALL CAPS - conceptual metaphors and domains; "italics" - metaphorical expressions quoted from headlines; italics - metaphorical expressions not directly excerpted from headlines; "regular" non-metaphorical expressions, such as quotations, terminology or implications.

10 Retrieved from http://www.dailymail.co.uk/news/article-2237617/Camerons-plan-allowgay-marriage-set-trigger-biggest-Tory-rebellion-modern-times.html

11 Retrieved from http://www.dailymail.co.uk/news/article-2082923/Mental-decline-Brainstarts-going-downhill-45.html

12 Retrieved from http://www.dailymail.co.uk/health/article-2244512/Britain-swamped-TBunless-tests-diagnose-brought-21st-century-experts-warn.html . Interestingly, the original wording of that headline was ...unless high-risk immigrants are routinely screened... with another metaphor contributing to stereotyping.

13 Retrieved from http://www.dailymail.co.uk/news/article-2250977/Federal-agents-hunt-JaneDoe-child-pornographer-FBI-appeal-trace-female-abuser-rescue-young-victim.html

14 Retrieved from http://www.dailymail.co.uk/news/article-2238631/Dean-Goodwin-Armedpolice-arrest-convicted-sex-offender-wanted-sexual-assault-woman.html

15 Retrieved from http://www.dailymail.co.uk/news/article-2092722/Pregnant-orang-utanhugs-daughter-bounty-hunters-Borneo-in.html

16 Retrieved from http://www.dailymail.co.uk/news/article-2085420/Europes-war-Britishjustice-UK-loses-human-rights-cases-damning-report-reveals.html

17 For more on personalization in this perspective see Molek-Kozakowska (2010).

18 Retrieved 13 January 2012 from http://www.dailymail.co.uk/news/article-2085957/Childbenefit-cuts-Camerons-vow-tackle-unfairness-system.html 
Retrieved 13 January 2012 from http://www.dailymail.co.uk/news/article-2085941/MichaelGove-wants-parents-classrooms-help-drive-standards.html

20 Retrieved 6 January 2012 from http://www.dailymail.co.uk/news/article-2082883/NHScare-David-Cameron-says-nurses-told-talk-patients-hospital-wards.html

21 Reference to emotion is one of the main ways of constructing newsworthiness, according to Bednarek and Caple (2012: 48-49, 55) billion-IMF-boosts-bailout-fund-1-TRILLION--World-Bank-warns-return-2008-09recession.html drives-fear-triple-dip-recession-exports-fall.html

24 Retrieved from http://www.dailymail.co.uk/news/article-2237682/Cosmetic-face-fillertimebomb-Doctors-crackdown-rising-toll-women-scarred-botched-skin-treatments.html Retrieved from http://www.dailymail.co.uk/news/article-2093265/Davos-2012-PrinceAndrew-pokes-fun-EU-nations-suffering-collapse-euro.html

\section{References}

Bednarek, Monika and Helen Caple (2012) News Discourse. London: Continuum.

Bell, Allan (1991) The Language of News Media. Oxford: Blackwell.

Bernstein, J. M. (1991) Introduction to The Culture Industry: Selected Essays on Mass Culture by Theodor W. Adorno. London: Routledge, 1-28.

Cap, Piotr (2006) Legitimization in Political Discourse: A Cross-disciplinary Perspective on the Modern US War Rhetoric. Newcastle: Cambridge Scholars.

Charteris-Black, Jonathan (2005) Politicians and Rhetoric: The Persuasive Power of Metaphor. Basingstoke: Palgrave.

Charteris-Black, Jonathan (2006) "Britain as a Container: Immigration Metaphors in the 2005 Election Campaign". Discourse and Society 17 (5), 563-581.

Chilton, Paul (1996) Security Metaphors: Cold War Discourse from Containment to Common House. New York: Peter Lang.

Chilton, Paul (2004) Analyzing Political Discourse: Theory and Practice. London: Routledge.

Chovanec, Jan (2010) "Legitimation through differentiation: Discursive construction of Jacques Le Worm Chirac as an opponent to military action.” In: Okulska, Urszula and Piotr Cap (eds.) Current Directions in Political Discourse Analysis: Methodological and Critical Perspectives. Amsterdam: John Benjamins, 61-81.

Chovanec, Jan (2014) Pragmatics of Tense and Time in News: From Canonical Headlines to Online News Texts. Amsterdam and Philadelphia: John Benjamins.

Coulson, Seana (2001) Semantic Leaps. Frame-shifting and Conceptual Blending in Meaning Construction. Cambridge: Cambridge University Press.

Fabiszak, Małgorzata (2007) A Conceptual Metaphor Approach to War Discourse and its Implications. Poznań: Adam Mickiewicz University Press.

Fairclough, Norman (1995) Media Discourse. London: Longman.

Fauconnier, Gilles and Mark Turner (2002) The Way we Think: Conceptual Blending and the Mind's Hidden Complexities. New York: Basic Books.

Fowler, Roger (1991) Language in the News: Discourse and Ideology in the Press. London: Routledge.

Gibbs, Raymond W. Jr. (ed.) (2008) The Cambridge Handbook of Metaphor and Thought. Cambridge: Cambridge University Press.

Goatly, Andrew (2007) Washing the Brain: Metaphor and Hidden Ideology. Amsterdam: John Benjamins. 
Grady, Jay (1999) “A Typology of Motivation for Conceptual Metaphors. Correlations vs. Resemblance". In: Gibbs, Raymond W. Jr and Gerard J. Steen (eds.) Metaphor in Cognitive Linguistics. Amsterdam: John Benjamins, 79-100.

Halliday, Michael A. K. (1985) An Introduction to Functional Grammar. London: Edward Arnold. Hart, Christopher (2010) Critical Discourse Analysis and Cognitive Science: New Perspectives on Immigration Discourse. Basingstoke: Palgrave.

Herrera Soler, Honesto (2008) “A Metaphor Corpus in Business Press Headlines.” Iberica 15, 51-70. Jeffries, Leslie (2010) Critical Stylistics: The Power of English. Basingstoke: Palgrave.

Johnson, Mark (2008) "Philosophy's Debt to Metaphor.” In: Gibbs, Raymond W. Jr. (ed.) The Cambridge Handbook of Metaphor and Thought, Cambridge: Cambridge University Press, 39-52.

Koller,Veronika (2005) "Critical Discourse Analysis and Social Cognition: Evidence from Business Media Discourse." Discourse and Society 16 (2), 199-224.

Kövecses, Zoltan (2005) Metaphor in Culture: Universality and Variation. Cambridge: Cambridge University Press.

Krzeszowski, Tomasz (1997) Angels and Devils in Hell: Elements of Axiology in Semantics. Warszawa: Wydawnictwo Energeia.

Lakoff, George (2002) Moral Politics: How Liberals and Conservatives Think. Chicago: Chicago University Press.

Lakoff, George (2008) “The Neural Theory of Metaphor.” In: Gibbs, Raymond W. Jr. (ed.) The Cambridge Handbook of Metaphor and Thought, Cambridge: Cambridge University Press, 17-38.

Lakoff, George and Mark Johnson (1980) Metaphors We Live By. Chicago: University of Chicago Press.

Molek-Kozakowska, Katarzyna (2009) "Metaphor as a Rhetorical Device in U.S. Interventionist Discourse: A CDA Review of Recent Metaphors of War and Terror." In: Wąsik, Zdzisław and Józef Zaprucki (eds.) Słowo jako wyraz duchowości człowieka. Jelenia Góra: Kolegium Karkonoskie, 55-70.

Molek-Kozakowska, Katarzyna (2010) "Personalization in Political Discourse: Its pragma-linguistic Realizations and Potential Persuasive Effects.” In: Witczak-Plisiecka, Iwona (ed.) Pragmatic Perspectives on Language and Linguistics: Pragmatics of Semantically-restricted Domains. Newcastle: Cambridge Scholars, 51-64.

Molek-Kozakowska, Katarzyna (2011) Discursive Exponents of the Ideology of Counterculture. Opole: Opole University Press.

Molek-Kozakowska, Katarzyna (2012) "Multiple Ideologies in the Media Construction of Women in Politics: A Case Study of Gender Parity Debate in Poland." Critical Approaches to Discourse Analysis across Disciplines (CADAAD) Journal 5 (2), 72-87.

Molek-Kozakowska, Katarzyna (2013) "Towards a Pragma-linguistic Framework for the Study of Sensationalism in News Headlines." Discourse and Communication 7 (2), 173-197.

Musolff, Andreas (2004) Metaphor and Political Discourse: Analogical Reasoning in Debates about Europe. Basingstoke: Palgrave.

Pragglejaz Group (2007) "MIP: A Method for Identifying Metaphorically Used Words in Discourse." Metaphor and Symbol 22 (1), 1-39.

Reah, Danuta (1998) The Language of Newspapers. London: Routledge.

Richardson, John (2007) Analysing Newspapers. Basingstoke: Palgrave.

Reisigl, Martin and Ruth Wodak (2001) Discourse and Discrimination. Rhetorics of Racism and Antisemitism. London: Routledge.

Sandikcioglu, Esra (2000) "More Metaphorical Warfare in the Gulf: Orientalist Frames in News Coverage." In: Barcelona, Antonio (ed.) Metaphor and Metonymy at the Crossroads: A Cognitive Perspective. Berlin: Mouton de Gruyter, 299-320.

Santa Ana, Otto (1999) “'Like an Animal I Was Treated': Anti-immigrant Metaphor in U.S. Public Discourse.” Discourse and Society 11 (1), 191-224. 
Sperber, Dan and Deirdre Wilson (2008) “A Deflationary Account of Metaphor". In: Gibbs, Raymond W. Jr. (ed.) The Cambridge Handbook of Metaphor and Thought, Cambridge: Cambridge University Press, 84-105.

Stern, Joseph (2008) "Metaphor, Semantics and Context." In: Gibbs, Raymond W. Jr. (ed.) The Cambridge Handbook of Metaphor and Thought, Cambridge: Cambridge University Press, 262-279.

Tannen, Deborah (1999) Argument Culture. New York: Ballantine Press.

Van Dijk, Teun A. (1998) Ideology: A Multidisciplinary Approach. London: SAGE.

Van Dijk, Teun A. (2001) “Critical Discourse Analysis.” In: Schriffin, Deborah, Deborah Tannen, and Heidi E. Hamilton (eds.) The Handbook of Discourse Analysis. Oxford: Blackwell, 352-371.

Van Dijk, Teun A. (2006) "Discourse and Manipulation." Discourse and Society 17 (2), 359-383.

Van Leeuwen, Theo (2007) "Legitimation in Discourse and Communication." Discourse and Communication 1 (1), 91-112.

Katarzyna Molek-Kozakowska, Ph.D., is assistant professor at the Institute of English, Opole University, Poland. Trained as a linguist, she now specializes in discourse analysis and media studies. She has published on various aspects of mass-mediated political discourse, rhetorical and stylistic properties of contemporary journalism and critical literacy.

Address: dr Katarzyna Molek-Kozakowska, Institute of English, Faculty of Philology, Opole University, Pl. Kopernika 11a, 45-040 Opole, Poland. [email: molekk@uni.opole.pl] 
